\title{
EVALUATION OF THE USE OF ALVEOLAR BLOCK FROM MAXILLARY TUBEROSITY FOR AUGMENTATION OF ANTERIOR MAXILLARY DEFECTS
}

\author{
Mohamed A. Aboushara' ${ }^{1}$ BDS, Mostafa M. Eldibany ${ }^{2} P h D$, Nagy P. Hassan² $P h D$
}

\begin{abstract}
INTRODUCTION: Maxillofacial bone defects occur for various reasons as infections, tumor and cysts or physiologic loss of bone after extraction of teeth. There are a lot of controversies among dental practitioners in the material used for filling of bone defects to increase the volume of bone in favor of good placement of the implant. Autogenous bone is the gold standard for bone reconstruction due to osteogenic, osteoinductive, and osteoconductive properties.

OBJECTIVES: The aim of this study was to evaluate clinically and radiographically the efficiency of using maxillary tuberosity as a block bone graft for augmentation of anterior maxillary defects.

MATERIALS AND METHODS: Twelve patients with anterior maxillary bone defects were treated with bone graft harvested from the maxillary tuberosity with an age range of 20 and 50 years old. Piezotome 2 was used for bone harvesting from the tuberosity. Osteosynthesis microscrews were used to fix the block graft in place.

RESULTS: Bone density and width showed statistical significant difference detected by cone beam computed tomography (CBCT).

CONCLUSIONS: The large and accessible maxillary tuberosity is a reliable source to use as autogenous bone block for augmentation of jaw defects

KEYWORDS: Autogenous bone graft, maxillary tuberosity, guided bone regeneration (GBR), piezosurgery.

1- Instructor of Oral and Maxillofacial Surgery, Department of Oral and Maxillofacial Surgery, Faculty of Dentistry, Alexandria University, Egypt.

2- Professor of Oral and Maxillofacial Surgery, Department of Oral and Maxillofacial Surgery, Faculty of Dentistry, Alexandria University, Egypt.
\end{abstract}

\section{INTRODUCTION}

Bony defects in the jaw occur for various reasons; they are caused by infections, tumors and cysts or physiologic loss of bone after extraction of teeth. Spontaneous bone regeneration in untreated defects is limited to small distance because of the rapid proliferation of surrounding soft tissues. The replacement of the defect with connective tissue often leads to a loss of stability accompanied by functional limitation and anatomical alteration which could be overcome by filling of the bone defect (1).

The treatment of partial and total loss of teeth with dental implants has become a routine treatment modality in dental practice. Nevertheless, tooth loss is frequently associated with loss of bone, often resulting in insufficient bone for dental implant placement $(2,3)$. During the past 25 years, surgical procedures have been developed to increase the local bone volume for implant placement (4). Numerous augmentation techniques have been proposed to increase alveolar bone dimensions, both vertically and horizontally. These techniques include: (1) guided bone regeneration (GBR); (2) bone block grafts; (3) distraction osteogenesis (DO); (4) ridge splitting or expansion; (5) osteotomies of the ridge or the jaws; and (6) combinations of the above (5-7).

There are a lot of controversies among dental practitioners in the material used for filling of bone defects to increase the height and the width of bone to place the implant in a favorable position. Autogenous bone is the gold standard for bone reconstruction due to its osteogenic, osteoinductive, and osteoconductive properties (8). Bone from the maxillary tuberosity has been harvested in particulate form for augmentation procedures for several years, (9) and has the advantages over other intraoral donor sites in that harvest is simple and with minimal complications (10). Tolstunov (11) was the first to introduce the potential of a maxillary tuberosity block graft in the treatment of localized bony defects in the maxilla for placement of implants (11). All transplanted bone grafts proceed through five stages: inflammation, revascularization by invasion of capillary buds into the graft, osteoinduction by differentiation of multipotent cells into osteoblasts, osteoconduction through ingrowth into the graft by means of the host, and finally remodeling (12).

Cortical bone grafts are used mostly for structural support and strength, and cancellous bone grafts for osteogenesis. Structural support and osteogenesis may be combined, one of the most important advantages of using cortico-cancellous bone grafts as bone blocks from maxillary tuberosity (13).

The aim of this study was to evaluate clinically and radio-graphically the efficiency of maxillary tuberosity as a block bone graft for augmentation of anterior maxillary defects.

\section{MATERIALS AND METHODS}

This study was a prospective clinical trial on 12 patients with bone defects in the anterior maxillary region treated by bone graft harvested from the maxillary tuberosity. The patients were selected from the outpatient clinic of the Oral and Maxillofacial Surgery Department, Faculty of Dentistry, Alexandria University. The ethical committee approval was obtained before the study began, and the selected patients were being informed about the nature of the study and signed an informed consent. 


\section{Inclusion criteria}

Patients with missing anterior maxillary tooth/teeth with associated horizontal defect according to classification suggested by Seibert et al. (14). Patients with enlarged maxillary tuberosity that is at least $1 \mathrm{~cm}$ long and $1 \mathrm{~cm}$ wide and with an accepted oral hygiene and willing to improve it. Patients with age range 20-50 years old. No gender preference in selection of the patients.

\section{Exclusion criteria}

Patients with medically compromised diseases as diabetes, systemic bone diseases which are contraindicated to graft placement affecting the clinical procedure or result and those exposed to chemotherapy or radiotherapy. Patients with disturbed occlusion, inadequate interarch space bruxism or clenching. Patients with maxillary third molar or with extreme pneumatization of the maxillary sinus in the area of maxillary tuberosity. Patients who smoked more than 10 cigarettes/day.

\section{Materials}

1. Piezotome 2 (Aceton Co., UK.) for pre-implant surgery was used. The Piezoelectric device consists of hand piece and foot switch that are connected to the main power unit. This has a holder for the hand piece and contains irrigation fluids that create an adjustable jet of $0-60$ $\mathrm{ml} / \mathrm{min}$ through a peristaltic pump removing debris from the cutting area and maintains a blood-free operating area because of cavitation (production of imploding bubbles) of the irrigation solution giving greater visibility particularly in difficult anatomical areas by dispersing coolant fluid as an aerosol. Power is controlled by selecting the type of bone to be cut (D1, D2, D3, and D4). (Fig. 1)

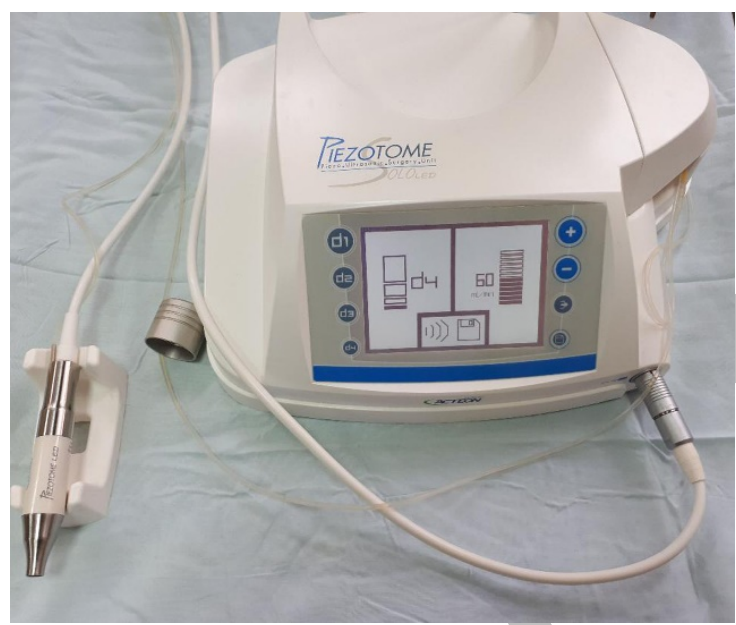

Figure (1): The piezosurgery device (piezotome).

In this study during harvesting bone from maxillary tuberosity, the device is adjusted on D3 or D4 and the irrigation was adjusted on $60 \mathrm{ml} / \mathrm{min}$ with the use of BS1S tip which is Ultra-sharp and robust saw, equipped with sharpened teeth, intended for in-depth cutting of bone with $9 \mathrm{~mm}$ cutting depth. The BS1 saw marked every $3 \mathrm{~mm}$, creates the lines of osteotomy.

2. Osteosynthesis micro screw (Antonhib, Germany): Micro-screws are made of titanium with width ranging from 1.1 to $1.8 \mathrm{~mm}$ and their length comes in 9, 11, 15 $\mathrm{mm}$. they are used to fix the block graft in place.

\section{Methods}

I. Preoperative assessment

1. History

\section{a) Personal history}

The patient data was collected and recorded in full details including name, age, gender, occupation, address, telephone number.

\section{b)Past medical and dental history}

Patients were asked about their medical status, smoking and their previous dental treatments.

\section{Clinical examination}

Was performed both extra orally and intra orally.

\section{A. Inspection (intra oral and extra oral)}

To detect any swelling, asymmetry malocclusion, texture of the mucosa, presence of any ulceration, hypertrophy or draining sinuses.

\section{B. Palpation (intra oral and extra oral)}

Palpation of the buccal, labial and palatal mucosa and the site of bone harvesting at the maxillary tuberosity.

\section{Radiographic examination}

A routine orthopantomogram for each patient followed by Cone beam computed tomography (CBCT) was done to evaluate bone width and height in both the recipient and donor sites.

\section{Surgical procedure}

All patients were operated under local anesthesia.The oral cavity was prepared by chlorhexidine gluconate (Hexitol: the Arab Drug Company, Cairo, A.R.) mouth rinses solution for thirty seconds. A horizontal mid-crestal incision with bard parker blade no.12 was done in the maxillary tuberosity area and extended to second upper molar area with vertical incisions $4 \mathrm{~mm}$ long using bard parker blade no. 15. , then a full-thickness flap was reflected by periosteal elevator to expose the surgical site. Access to the recipient site was gained through a full thickness mucoperiosteal pyramidal flap (2 or 3 lines) using bard parker blade no. 15 at the anterior maxillary defect. (Fig. 2)

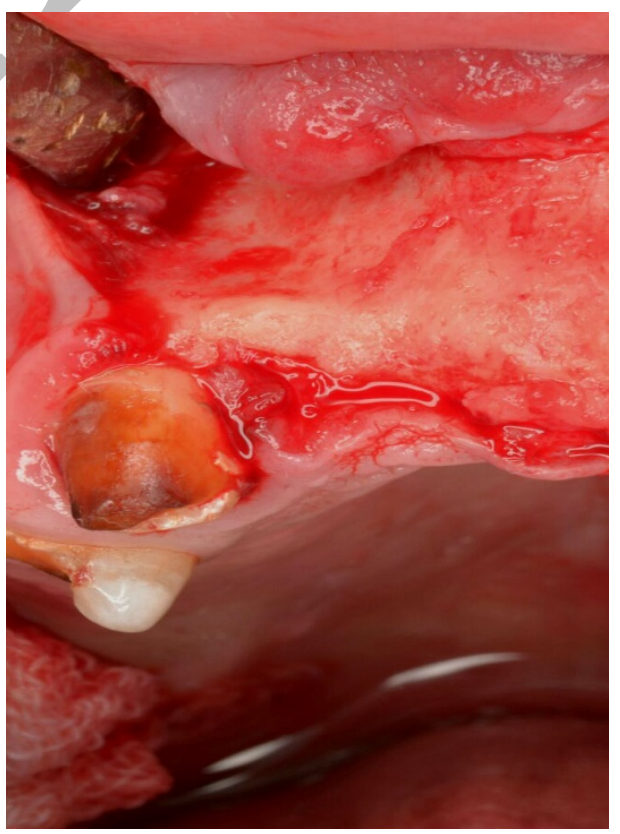

Figure (2): The reflection of the mucoperiosteal flap showing the bony defect. 
Surface decortication was done in the recipient site to improve future vascularization of the graft. (Fig. 3)

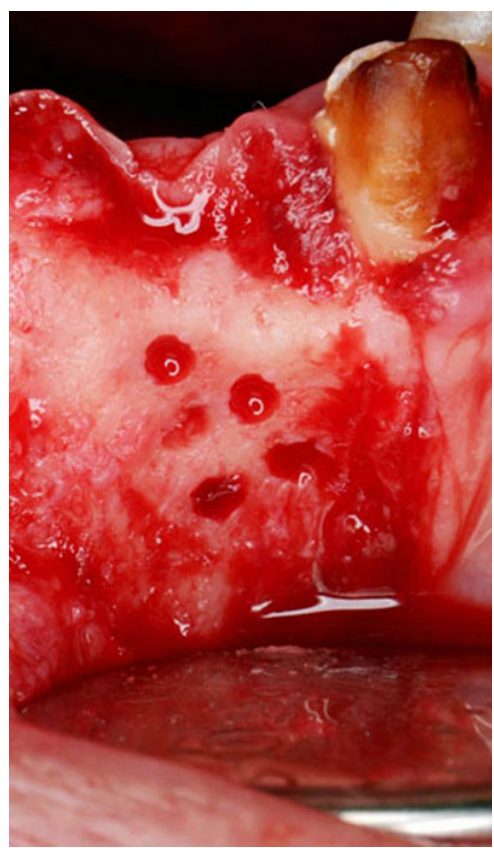

Figure (3): Decortication of bone in the recipient site.

Harvesting of bone was done by the use of BS1S tip on piezotome 2 (adjusted on D3 or D4 type of bone) at the donor site according to the measurements taken from CBCT radiographically and from calipers clinically. Bone was taken from the buccal side of maxillary tuberosity. (Fig. 4)
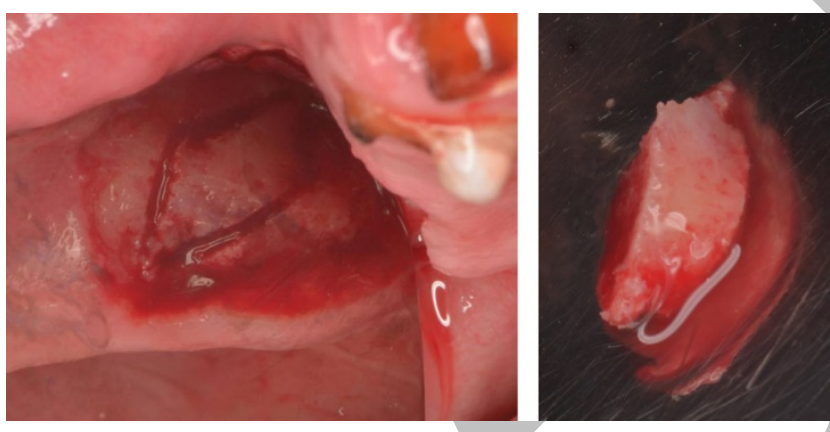

Figure (4): A) the harvesting of bone block from maxillary tuberosity in donor site using piezotome. B). the bone block after harvesting in saline solution.

Closure of the flap at the donor site was done by horizontal mattress silk sutures 3/0 after smoothening of bony irregularities and irrigation by saline. The graft was preserved in saline. The surface irregularities were smoothened. The harvested graft was shaped and adapted to the recipient site and fixed by micro-screw. (Fig. 5) Flap repositioning and closed by a horizontal mattress sutures using black silk suturing material.

\section{Postoperative instructions including}

Extra-oral ice packs during the first day every one hour and maintain daily routine oral hygiene after surgery.

All patients received postoperative medications including:

- Antibiotics (Amoxicillin clavulanic acid 1 gm) every 12 hours for 5 days (Augmentin, Glaxosmith Kline, UK).
- Non-steroidal anti-inflammatory drugs (Diclofenac potassium $50 \mathrm{mg}$ ) every eight hours for 5 days (Cataflam (50mg), Novartis, Switzerland).

- Anti-inflammatory and antiedematous (Chymotrypsin 300 E.A.U and Trypsin E.A.U) every eight hours for 5 days (Alphintern, Amoun Pharmaceutical Company, Egypt).

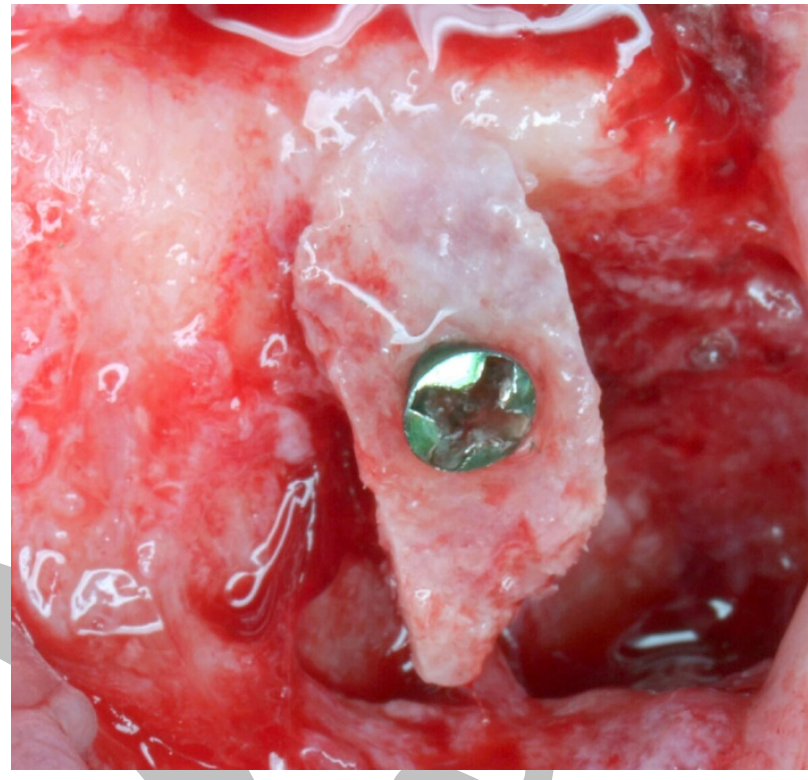

Figure (5): The bone block fixed in place with micro-screw in the recipient site.

Follow up phase

A thorough Follow-up was performed after 24-hours, one week and two weeks for the assessment of the following clinical parameters: postoperative pain and edema.

Follow up radiographically in the recipient site for bone gain and density was done preoperatively, immediately postoperative and after 6 months using cone beam computed tomography.

\section{CBCT specifications}

Exposure was performed using veraviewepocs 3D R100 (J.morita, Japan, at $8 \mathrm{~mA}, 90 \mathrm{KV}$ ). Image reconstruction was performed using special software Ondemand3D (Version 1.0.9, Cybermed, Korea). Standardization during imaging was achieved through adjusting the patient positioning and lights as follows:

1. the seat height was adjusted to position the region of interest (ROI) vertically within the field of view (FOV).

2. The upper light beam indicated the top of the FOV and the lower light beam indicated the bottom of the FOV.

3. The sagittal light (vertical front light) was positioned in the center of the FOV from sagittal direction so that it is in the center of the ROI.

4. The lateral light (vertical side light) was positioned in the center of the FOV in the lateral direction so that it is in the center of the ROI.

5. The patient was instructed not to move during the duration of exposure.

\section{Evaluation of bone width and density}

All measurements were performed using OnDemand3D software. Immediate Postoperative cuts were conducted with the same apparatus and settings as the preoperative scans. Radiographic bone density was evaluated using the same software. Measurements were taken as follows: a. the bone density was used as a known measurement in 
Hounsfield Unit (HU) b. From the tool bar, the implant bone density was selected from task section. c. The desired area was selected, right click pressed and bone density was chosen. d. Mean, standard deviation, minimum and maximum readings were automatically displayed by the system.

\section{Statistical analysis of the data}

Data were fed to the computer and analyzed using IBM SPSS software package version 20.0. (Armonk, NY: IBM Corp) Qualitative data were described using number and percent. The Kolmogorov-Smirnov test was used to verify the normality of distribution Quantitative data were described using range (minimum and maximum), mean, standard deviation and median. Significance of the obtained results was judged at the $5 \%$ level.

\section{The used tests were}

\section{1 - ANOVA with repeated measures}

For normally distributed quantitative variables, to compare between more than two periods or stages, and Post Hoc test (LSD) (Bonferroni adjusted) for pairwise comparisons

\section{2 -Wilcoxon signed ranks test}

For abnormally distributed quantitative variables, to compare between two periods

\section{RESULTS}

All patients were free from any systemic disease that can compromise the bone grafting success.A total of twelve patients with bony defects in the anterior maxillary region. They were treated with bone graft that harvested from the maxillary tuberosity and fixed in the recipient site by one micro-screw of $1.2 \mathrm{~mm}$ diameter and 9 or $11 \mathrm{~mm}$ in length according to the case. The recipient areas were in maxillary central or lateral or canine region. The size of harvested block was about 2 to $4 \mathrm{~mm}$ in width and 5 to $7 \mathrm{~mm}$ in length according to the size of the defect. Their ages ranged from 28 to 50 years old with mean age of 35.5 years. The number of males and females was 8 females to 4 males. The ratio between males and females was 1:2 without gender predilection.

All patients were followed up for 6 months after graft placement, and results were registered as regards to clinical and radiographic evaluation.

\section{Radiographic evaluation}

Bone densities and widths were measured preoperatively, immediately after bone graft placement and after 6 month of healing (Fig. 6) in the previously defects using:
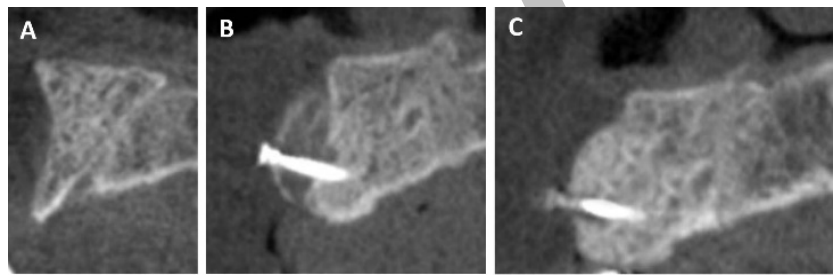

Figure (6): The cross section CBCT cuts in the recipient site: Apreoperatively, B-immediate postoperative, C-After 6 months.

\section{A- Cone beam computed tomography (CBCT) for} measurement of bone density in Hounsfield units

The CBCT recorded and tabulated as in (Table 1)

preoperatively before autogenous bone graft placement, the mean bone density inside the defective area was $523.49 \pm$ 158.17 with a minimum recorded value of 249.90 and a maximum recorded value of 783.50 . While the mean bone density immediately postoperatively for the same area was $484.88 \pm 165.56$ with a minimum recorded value of 233.30 and a maximum recorded value of 763.30 . The difference in bone densities between the two time of periods was found to be statistically significant $\mathrm{p} 1=0.001^{*}$.

After six months, the mean bone density value was $547.52 \pm 172.69$ with a minimum recorded value of 262.4 and a maximum recorded value of 841.70 .

The mean bone density value immediately after bone graft placement and six months later was found to be statistically significant ( $3<<0.001^{*}$ ), and was also found to be statistically significant with the bone density value preoperatively $\cdot\left(\mathrm{p} 2=0.008^{*}\right)$.

Table (1): Descriptive analysis of the studied cases according to bone density $(\mathrm{n}=12)$

\begin{tabular}{||c|c|c|c|c|c||}
\hline \multirow{2}{*}{ Bone Density } & \multirow{2}{*}{$\begin{array}{c}\text { Pre- } \\
\text { operativ } \\
\end{array}$} & \multicolumn{2}{|c|}{ Post-operative } & \multirow{2}{*}{ F } & P \\
\cline { 3 - 4 } & Immediately & 6 months & & \\
\hline Min. - & $249.90-$ & $233.30-$ & $262.4-$ & & \\
Max. & 783.50 & 763.30 & 841.70 & & \\
Mean \pm & $523.49 \pm$ & $484.88 \pm$ & $547.52 \pm$ & $35.537^{*}$ & $<0.00$ \\
SD. & 158.17 & 165.56 & 172.69 & & $1^{*}$ \\
Median & 497.45 & 471.55 & 535.70 & & \\
\hline Sig. & \multicolumn{2}{|c|}{$\mathrm{p}_{1}=0.001^{*}, \mathrm{p}_{2}=0.008^{*}, \mathrm{p}_{3}<0.001^{*}$} & & \\
\hline
\end{tabular}

F,p: $\mathrm{F}$ and $\mathrm{p}$ values for $\mathrm{F}$ test (ANOVA) with repeated measures for comparing between different period

p1: $p$ value for comparing between Pre-operative and Post-operative Immediately

p2: $p$ value for comparing between Pre-operative and after 6 months $\mathrm{p}_{3}$ : $\mathrm{p}$ value for comparing between Post-operative

Immediately and after 6 months

*: Statistically significant at $\mathrm{p} \leq 0.05$

\section{B- CBCT for measurement of bone width:}

Using CBCT to measure the bone gain and evaluated preoperatively, immediate post-operative and after 6 months. (Table 2)

Table (2): Descriptive analysis of the studied cases according to bone width $(\mathrm{n}=12)$

\begin{tabular}{||c|c|c|c|c|c||}
\hline \multirow{2}{*}{ Bone Width } & \multirow{2}{*}{ Pre-operative } & \multicolumn{2}{|c|}{ Post-operative } & \multirow{2}{*}{ F } & \multirow{2}{*}{ p } \\
\cline { 3 - 4 } & & Immediately & $\mathbf{6}$ months & & \\
\hline $\begin{array}{l}\text { Min. - } \\
\text { Max. }\end{array}$ & $2.05-4.23$ & $5.68-7.85$ & $3.69-7.54$ & & \\
$\begin{array}{l}\text { Mean } \pm \\
\text { SD. }\end{array}$ & $3.36 \pm 0.62$ & $6.83 \pm 0.81$ & $5.86 \pm 1.35$ & $109.689^{*}$ & $<0.001^{*}$ \\
Median & 3.38 & 6.71 & 6.15 & & \\
\hline Sig. & \multicolumn{2}{|c|}{$\mathrm{p}_{1}<0.001^{*}, \mathrm{p}_{2}<0.001^{*}, \mathrm{p}_{3}=0.001^{*}$} & & \\
\hline
\end{tabular}

F,p: $\mathrm{F}$ and $\mathrm{p}$ values for $\mathrm{F}$ test (ANOVA) with repeated measures for comparing between different period

p1: $p$ value for comparing between Pre-operative and Postoperative Immediately

p2: p value for comparing between Pre-operative and after 6 months

pз: $p$ value for comparing between Post-operative Immediately and after 6 months

*: Statistically significant at $\mathrm{p} \leq 0.05$

Preoperatively before autogenous bone graft placement, the mean bone width of the defective area $3.36 \mathrm{~mm} \pm 0.62$ 
mm with a minimum recorded value $2.05 \mathrm{~mm}$ and a maximum recorded value $4.23 \mathrm{~mm}$. While the mean bone width immediately postoperatively for the same area was $6.83 \mathrm{~mm} \pm 0.81 \mathrm{~mm}$ with a minimum recorded value of 5.68 $\mathrm{mm}$ and a maximum recorded value of $7.85 \mathrm{~mm}$. The difference in bone width between the two time periods was found to be statistically significant $\mathrm{p} 1<0.001$.

After six months, the mean bone width value was 5.86 $\mathrm{mm} \pm 1.35 \mathrm{~mm}$ with a minimum recorded value of $3.69 \mathrm{~mm}$ and a maximum recorded value of $7.54 \mathrm{~mm}$.

The mean bone width value immediately after bone graft placement and six months later was found to be statistically significant ( $\mathrm{p} 3=0.001)$, and was also found to be statistically significant with the bone width value preoperatively .( p2<0.001).

\section{DISCUSSION}

In this study we used CBCT scan which is useful in determining bone quantity, bone width, height and proximity of adjacent structures; it may lack the ability to quantify bone quality and density in a meaningful manner but in agreement with a study done by Reeves et al. (15) which demonstrated a clinical application of a method developed by Mah et al. (16) to derive Hounsfield units using grey levels in the CBCT volume. The application of this method to derive Hounsfield units can provide a standardized method to assess bone quality similar to that found in medical CT (15).

From the results of this study, piezotome provides precise, clean and smooth cutting with excellent visibility. Piezoelectric surgery systems use ultrasonic micro vibrations to create an osteotomy. These micro vibrations make selective bone cuts possible (17). The piezotome does not work on soft tissue, so the device causes little or no soft tissue trauma during intraoral bone harvesting. In addition, surgical access is easier in the deep oral cavity in comparison to surgical burs, which use a straight hand piece. The piezo surgery device makes a precise and tactilecontrolled osteotomy.(17)

In agreement with the study done by Happe (18) on bone grafts that harvested from the mandibular ramus by piezosurgery in 40 patients and found that all transplanted bone grafts integrated without major complications, provided sufficient bone for implant placement, the complication rate at the donor sites was low, resorption of most grafts was minimal and the graft size obtained was comparable with that seen using conventional techniques.

In contrast to Chiriac et al. (19) who did not find any significant differences between piezosurgery and conventional rotating drills in collecting cortical bone chips in terms of their detrimental effects on viability and differentiation of cells growing out of autogenous bone chips derived from intraoral cortical sites (19).

Before placing the graft, the cortical bone surface is perforated with a small round bur to stimulate bleeding into the defect area and to open marrow spaces which is called decortication or bone marrow penetration (20).

In agreement with a study done by Lundgren (21) who found advantages from decortication as: (1) to enhance the healing process by promoting bleeding and blood clot formation; (2) to allow progenitor cells and blood vessels to reach the bone graft site (21-23) which facilitate angiogenesis; and (3) to improve the physical interlocking of grafted bone and a recipient site (24-26). On the other hand, Decortication may also have some negative effects; additional blood loss, potentially greater postoperative pain, increased bone loss, and increased operative time (27).

In the study, the bone width and density were assessed immediately post-operative and after 6 months. From the results of this study, Maxillary tuberosity provides corticocancellous bone blocks used for augmentation of anterior maxillary horizontal defects with 4 to $6 \mathrm{~mm}$ bone loss combining the structural support of cortical graft and osteogenesis of cancellous grafts. Comparing the volume of Maxillary tuberosity bone block with chin blocks, Montazem et al. (28) who found that chin block grafts which is cortico-cancellous in nature can provide larger amount of bone quantity. Although the maxillary tuberosity offer less amount of bone than ramus and chin grafts, it has many advantages over them regarding the complications and post-operative pain.

In agreement with a study done by Khojasteh et al. (29) stated that tuberosity alveolar block bone grafts is a valuable source of bone in augmentation of alveolar ridges deficient in width.

In contrast to a study done by Chen et al. (30) who stated that harvesting bone from maxillary tuberosity is not well documented and the quality and the quantity of the bone is often poor.

In this study the pain and edema was assessed 24 hours, one week and two weeks after the surgical procedure. Comparing the results with Garg (31) who listed series of complications associated with ramus block grafts including potential damage to the inferior alveolar nerve, incision dehiscence in donor area, postoperative trismus and potential damage to the lingual nerve during flap incision. No nerve injuries, dental injuries, or tears of the Schneiderian membrane were noted from the harvesting procedure in any of cases of this study.

In agreement with Silva et al (32) who compared complications of intraoral donor sites for bone grafting, reported that the major discomfort reported by patients was some degree of sensory deficit in the lower lip and mental area. Comparatively, it was found in $16 \%$ of cases after chin grafting and in $8.3 \%$ of cases after ramus grafting. No complications were found involving the maxillary tuberosity graft. As with other autogenous bone grafts that taken from intraoral or extra oral sites, there is always a possibility of resorption of the graft after approximately 4 to 6 months if bone is not loaded with implants $(33,34)$.

\section{CONCLUSION}

From the results of this study we can conclude that: The large and accessible maxillary tuberosity is a reliable source to use as autogenous bone block for augmentation of jaw defects. The harvesting of bone blocks is generally easier and safer with piezo surgery, but is more time consuming.

\section{CONFLICT OF INTEREST}

The authors declare that they have no conflicts of interest.

\section{REFERENCES}

1. Palti A, Hoch T. A concept for the treatment of various dental bone defects. Implant Dent. 2002;11(1):73-8.

2. Belser UC, Schmid B, Higginbottom F, Buser D. Outcome analysis of implant restorations located in the anterior 
maxilla: a review of the recent literature. Int $\mathrm{J}$ Oral Maxillofac Implants. 2004;19:30-42.

3. Higginbottom F, Belser U, Jones JD, Keith SE. Prosthetic management of implants in the esthetic zone. Int J Oral Maxillofac Implants. 2004;19:62-72.

4. Khojasteh A, Soheilifar S, Mohajerani H, Nowzari H. The effectiveness of barrier membranes on bone regeneration in localized bony defects: a systematic review. Int J Oral Maxillofac Implants. 2013;28(4).

5. Aghaloo TL, Moy PK. Which hard tissue augmentation techniques are the most successful in furnishing bony support for implant placement? Int J Oral Maxillofac Implants. 2007;22:49-70.

6. Chiapasco M, Casentini P, Zaniboni M. Bone augmentation procedures in implant dentistry. Int J Oral Maxillofac Implants. 2009;24 Suppl:237-59.

7. Jensen SS, Terheyden H. Bone augmentation procedures in localized defects in the alveolar ridge: clinical results with different bone grafts and bone-substitute materials. Int J Oral Maxillofac Implants. 2009;24:218-36.

8. Hassani A, Khojasteh A, Shamsabad AN. The anterior palate as a donor site in maxillofacial bone grafting: a quantitative anatomic study. J Oral Maxillofac Surg. 2005;63(8):1196-200.

9. Singh S. Management of infrabony defects in mandibular molars in a patient with generalized aggressive periodontitis using autogenous bone graft from maxillary tuberosity. J Indian Soc Periodontol. 2010;14(1):53-6.

10. Khojasteh A, Behnia H, Soleymani Shayesteh Y, Morad G, Alikhasi M. Localized bone augmentation with cortical bone blocks tented over different particulate bone substitutes: a retrospective study. Int J Oral Maxillofac Implants. 2012;27(6).

11. Tolstunov L. Maxillary tuberosity block bone graft: innovative technique and case report. J oral Maxillofac Surg. 2009;67(8):1723-9.

12. Gomes KU, Carlini JL, Biron C, Rapoport A, Dedivitis RA. Use of allogeneic bone graft in maxillary reconstruction for installation of dental implants. J Oral Maxillofac Surg. 2008;66(11):2335-8.

13. Brydone A, Meek D, Maclaine S. Bone grafting, orthopaedic biomaterials, and the clinical need for bone engineering. Proc Inst Mech Eng H. 2010;224(12):1329-43.

14. Seibert JS. Reconstruction of deformed, partially edentulous ridges, using full thickness onlay grafts. Part I. Technique and wound healing. Compend Contin Educ Dent. 1983;4(5):437-53.

15. Reeves TE, Mah P, McDavid WD. Deriving Hounsfield units using grey levels in cone beam CT: a clinical application. Dentomaxillofac Radiol. 2012;41(6):500-8.

16. Mah P, Reeves TE, McDavid WD. Deriving Hounsfield units using grey levels in cone beam computed tomography. Dentomaxillofac Radiol. 2010;39(6):323-35.

17. Sohn DS, Ahn MR, Lee WH, Yeo DS, Lim SY. Piezoelectric osteotomy for intraoral harvesting of bone blocks. Int J Periodontics Restorative Dent. 2007;27(2):127-31.

18. Happe A. Use of a piezoelectric surgical device to harvest bone grafts from the mandibular ramus: report of 40 cases. Int J Periodontics Restorative Dent. 2007;27(3):2419.

19. Chiriac G, Herten M, Schwarz F, Rothamel D, Becker J. Autogenous bone chips: influence of a new piezoelectric device (Piezosurgery) on chip morphology, cell viability and differentiation. J Clin Periodontol. 2005;32(9):994-9.

20. Buser D. years of guided bone regeneration in implant dentistry, 2010. New Malden: Quintessence Publishing Co Ltd; 2009.

21. Lundgren AK, Lundgren D, Hammerle CH, Nyman S, Sennerby L. Influence of decortication of the donor bone on guided bone augmentation. An experimental study in the rabbit skull bone. Clin Oral Implants Res. 2000;11(2):99106.

22. Buser D, Brägger U, Lang N, Nyman S. Regeneration and enlargement of jaw bone using guided tissue regeneration. Clin Oral Implants Res. 1990;1(1):22-32.

23. Schmid J, Wallkamm B, Hammerle CH, Gogolewski S, Lang NP. The significance of angiogenesis in guided bone regeneration. A case report of a rabbit experiment. Clin Oral Implants Res. 1997;8(3):244-8.

24. Alberius P, Gordh M, Lindberg L, Johnell O. Onlay bone graft behaviour after marrow exposure of the recipient rat skull bone. Scand J Plast Reconstr Surg Hand Surg. 1996;30(4):257-66.

25. Alberius P, Gordh M, Lindberg L, Johnell O. Effect of cortical perforations of both graft and host bed on onlay incorporation to the rat skull. Eur J Oral Sci. 1996;104(56):554-61.

26. Gordh M, Alberius P, Lindberg L, Johnell O. Bone graft incorporation after cortical perforations of the host bed. Otolaryngol Head Neck Surg. 1997;117(6):664-70.

27. Greenstein G, Greenstein B, Cavallaro J, Tarnow D. The role of bone decortication in enhancing the results of guided bone regeneration: a literature review. J Periodontol. 2009;80(2):175-89.

28. Montazem A, Valauri DV, St-Hilaire H, Buchbinder D. The mandibular symphysis as a donor site in maxillofacial bone grafting: a quantitative anatomic study. J Oral Maxillofac Surg. 2000;58(12):1368-71.

29. Khojasteh A, Nazeman P, Tolstunov L. Tuberosity-alveolar block as a donor site for localised augmentation of the maxilla: a retrospective clinical study. Br J Oral Maxillofac Surg. 2016;54(8):950-5.

30. Chen ST, Beagle J, Jensen SS, Chiapasco M, Darby I. Consensus statements and recommended clinical procedures regarding surgical techniques. Int $\mathrm{J}$ Oral Maxillofac Implants. 2009;24 Suppl:272-8.

31. Garg AK. Bone. Biology, harvesting, grafting for dental implants (Rationale and Applications). 2004:3-20.

32. Silva FMS, Cortez ALV, Moreira RWF, Mazzonetto R. Complications of intraoral donor site for bone grafting prior to implant placement. Implant Dent. 2006;15(4):420-6.

33. Araujo M, Sonohara M, Hayacibara R, Cardaropoli G, Lindhe J. Lateral ridge augmentation by the use of grafts comprised of autologous bone or a biomaterial. An experiment in the dog. $\mathrm{J}$ Clin Periodontol 2002;29(12):1122-31.

34. Urbani G, Lombardo G, Santi E, Tarnow D. Localized ridge augmentation with chin grafts and resorbable pins: case reports. Int $\mathrm{J}$ Periodontics Restorative Dent. 1998;18(4):363-75. 